Silva, ALS, Moura, PRG \& Nogara, PA (2020). A model of systematization to experimentation in Science Teaching: Problematized Experimental Activity (PEA). Research, Society and Development. 9(7): 1-19, e187974012.

\title{
Um modelo de sistematização à experimentação no Ensino de Ciências: Atividade Experimental Problematizada (AEP)
}

A model of systematization to experimentation in Science Teaching: Problematized Experimental Activity (PEA)

Un modelo de sistematización a la experimentación en la Enseñanza de Ciencias:

\section{Actividad Experimental Problematizada (AEP)}

Recebido: 27/04/2020 | Revisado: 27/04/2020 | Aceito: 01/05/2020 | Publicado: 03/05/2020

\section{André Luís Silva da Silva}

ORCID: https://orcid.org/0000-0002-8245-9389

Universidade Federal do Pampa, Brasil

E-mail: andresilva@unipampa.edu.br

Paulo Rogério Garcez de Moura

ORCID: https://orcid.org/0000-0003-2659-5383

Universidade Federal do Espírito Santo, Brasil

E-mail: paulomoura.ufes@gmail.com

Pablo Andrei Nogara

ORCID: https://orcid.org/0000-0002-9133-6102

Universidade Federal de Santa Maria, Brasil E-mail: pbnogara@gmail.com

\section{Resumo}

Se apresenta e se discute neste artigo a conformação de uma estratégia pedagógica ao Ensino de Ciências, nas particularidade das Ciências experimentais, intitulada de Atividade Experimental Problematizada (AEP), a partir de uma sistematização teórico-metodológica subsidiada por eixos articuladores teóricos e momentos metodológicos. Objetiva-se, com isso, a caracterização de um estratagema de ensino potencialmente problematizável em sua condução e nas reflexões que origina capaz de favorecer a construção psicológica de um conhecimento científico com efetiva compreensão de seus aspectos circunscritos, subsidiado pela processualidade relacional teoria-prática.

Palavras-chave: Ensino de Ciências; Experimentação; Problematização. 


\section{Abstract}

The conformation of a pedagogical strategy to science teaching is presented and discussed in this article, in the particularities of experimental sciences, entitled Problematic Experimental Activity (PEA), based on a theoretical-methodological systematization supported by theoretical articulating axes and moments methodological. Thus, the objective is to characterize a teaching stratagem that is potentially problematic in its conduct and in the reflections it originates, capable of favoring the psychological construction of scientific knowledge with an effective understanding of its circumscribed aspects, subsidized by the theory-practice relational processuality.

Keywords: Science Teaching; Experimentation; Problematization.

\section{Resumen}

La conformación de una estrategia pedagógica para la enseñanza de las ciencias se presenta y discute en este artículo, en las particularidades de las ciencias experimentales, titulada Actividad Experimental Problemática (AEP), basada en una sistematización teóricometodológica apoyada en ejes y momentos de articulación teórica. metodologico. Por lo tanto, el objetivo es caracterizar una estratagema de enseñanza que sea potencialmente problemática en su conducta y en las reflexiones que origina, capaz de favorecer la construcción psicológica del conocimiento científico con una comprensión efectiva de sus aspectos circunscritos, subsidiados por la procesualidad relacional teoría-práctica.

Palabras clave: Enseñanza de las Ciencias; Experimentació; Problematización.

\section{Introdução}

Ampla literatura específica defende a experimentação como uma metodologia altamente contributiva aos processos do ensino e da aprendizagem em Ciências; diversos autores tem nas últimas décadas se dedicado ao estudo, reflexão e sistematização dos aspectos teóricometodológicos imbuídos nas atividades experimentais e em seus derivados sistêmicos pedagógicos (Cachapuz, 2005; Gil Peres, 1993; Gil; Castro, 1996; Galiazzi \& Gonçalves, 2004; Perrenoud, 2000).

À guisa disso, a Atividade Experimental Problematizada (AEP) configura-se, como uma proposta de sistematização teórico-metodológica direcionada ao ensino experimental das Ciências. Está concretizada originalmente pela publicação de duas obras bibliográficas nas quais, na primeira, Silva \& Nogara (2018) apresentam exemplificações de AEP no contexto do ensino da Química e, na segunda, Silva \& Moura (2018) a estendem às demais Ciências, 
fundamentando-o pedagógica e, epistemologicamente. Outrossim desde 2015, artigos versam sobre a temática (Silva, Moura \& Del Pino, 2015; 2017; 2018; Silva, Ferreira, Pereira \& Filho, 2019; Moreira, Silva, Moura \& Del Pino, 2019), em âmbitos de ensino e de aprendizagem das Ciências, em diferentes contextos e públicos-alvo.

\section{Atividade Experimental Problematizada (AEP)}

Conforme referido, denominamos de, e nos referimos como, Atividade Experimental Problematizada - AEP - a uma proposta de ensino-aprendizagem, nas particularidades das Ciências experimentais, que se estrutura a partir da demarcação de um problema de natureza teórica, isto é, como uma atividade prática que objetiva a busca por uma solução a dada situação-problema. No contexto de uma AEP, o próprio problema apresentado ao aluno pode despertar nele sua motivação, interesse, desafio intelectual e capacidade de discussão e de articulação de ideias, promovendo a autoconfiança necessária para que busque apresentar explicações idiossincráticas aos fenômenos/situações observados. Todavia, para que essa metodologia de ação possa ser bem sucedida, o professor não deve fornecer (e tampouco esperar por) respostas definitivas, previamente determinadas, mas suscitar processualmente novos questionamentos e desafios, no intuito de levar o aluno a formular e reformular - seu próprio entendimento (Carvalho, Vannucchi \& Barros, 2007).

Sob esta ótica, o professor assume a função de questionador, conduzindo perguntas e propondo problemas, auxiliando seus alunos na exploração, desenvolvimento e adequação constante de suas próprias concepções, para que eles venham a sugerir hipóteses e justificativas às aparentes inconsistências com as quais se deparam (Hodson, 1994). O ensino experimental fundamentado na busca por solução a problemas articula-se à característica que a vida cotidiana tem de apresentar desafios, e incentiva os alunos a aperfeiçoarem seus métodos e habilidades heurísticas, potencialmente tornando-os capazes de coletar, sistematizar, analisar, compreender e comunicar dados e informações, e de operar neles transformações rumo a novos conhecimentos para responder a novos desafios.

Ensinar a resolver problemas não consiste somente em dotar os alunos de habilidades e estratégias eficazes, mas também em criar neles o hábito e a atitude de enfrentar a aprendizagem como um problema para o qual deve ser encontrada uma resposta. Não é uma questão de somente ensinar a resolver problemas, mas também de ensinar a propor problemas para si mesmo, a transformar a realidade em um problema que mereça ser questionado e estudado (Pozo, 1998, p. 15). 
No próprio fazer experimental, um problema termina por se subdividir em inúmeros outros problemas que devem ser considerados e solucionados para que se chegue a uma resposta aceitável. A habilidade de propor problemas (ou problemas derivados), assim, é essencial para a prática experimental, razão pela qual a mera execução de um roteiro experimental em não raros casos atua como redutora de tal prática.

O aporte teórico da proposta da AEP aqui defendida caracteriza os alunos como sujeitos que desenvolvem conhecimentos em um processo no qual o professor assume e desempenha o papel de orientador, cuja genuinidade é específica, mas abrangente. Cabe assim a constante supervalorização das perguntas em relação às suas possíveis respostas, em um movimento pedagógico dinâmico. Em conformidade ao que destaca, Santos (2008, p. 126), “[...] o papel do professor não está em revelar a realidade aos educandos, mas em ajudá-los a desvendar a realidade por si só". Sob este olhar, torna-se oportuna a compreensão de que o objetivo da experimentação não deve configurar-se na formação ou doutrinação do aluno a pensar/agir de modo padronizado, mas despertar nele uma concepção crítica e reflexiva da realidade, bem como sua capacidade de tomada de decisões, que o auxilie, tanto cognitivamente na compreensão do fenômeno em si, como socialmente, na transposição que poderá fazer dos saberes tratados.

Nesse enfoque, métodos, resultados e conclusões heterogêneos devem ser aceitos e, inclusive, incentivados, uma vez que, de acordo com Latour \& Woolgar (1997, p. 61), “[...] na verdade, os fenômenos dependem do material, eles são totalmente constituídos pelos elementos utilizados no laboratório". Neste contexto, a experimentação se desprende de sua função (redutora) de simples confirmadora da instância teórica, normalmente já previamente desvelada, adquirindo uma dimensão afirmadora de possíveis interpretações plausíveis dessa instância.

À guisa disso, considera-se a possibilidade de os alunos virem a estabelecer conexões próprias entre a atividade realizada experimentalmente e os aportes teóricos, conceituais e proposicionais, correlacionados e fundantes aos temas tratados, sendo

[...] a ciência uma construção humana, deve-se reconhecer que no fazer ciência se desenvolve um processo de representação da realidade em que predominam acordos simbólicos e linguísticos num exercício continuado de discursos mentais, íntimos ao sujeito, e discursos sociais, propriedade do coletivo (Giordan, 1999, p. 46).

Para isso advir, deve-se evitar um massivo espaço-tempo destinado à realização do experimento e um curto período reservado à sua reflexão e do que dela resulta. No propósito 
da estruturação de uma concepção mais elaborada, isto é, de uma fundamentação sofisticada sobre o fazer experimental, capaz de incentivar um estratagema investigativo, a AEP propõe a leitura, a escrita, a fala e a discussão (contextualizados a amplas realidades) como indissociáveis das manipulações e observações experimentais (Francisco, Ferreira \& Hartwig, 2008). Logo, deve-se considerar que o

[...] pressuposto de que se deva, no ensino, esgotar um conceito para poder aplicá-lo pode ser questionado, pois é justamente nas aplicações do conceito que se explicitarão as relações a serem estabelecidas entre os conceitos. Além disso, existem tendências na psicologia contemporânea que consideram os conceitos inseparáveis dos contextos de aplicação, uma vez que o aluno tende a recuperar conceitos a partir desses contextos de aplicação e não no vazio (Mortimer, Machado \& Romanelli, 2000, p. 275).

A inserção em um laboratório de Ciências, tendo em vista uma abordagem e processualidade pedagógico-científica problematizada pode, por si, estimular a curiosidade investigativa dos alunos, quando eles são desafiados cognitivamente. Contudo, não é imprescindível, sob um estereótipo padrão, convencional. Tampouco a mera inclusão do aluno em ambientes de atividades práticas representa uma fonte suficiente de motivação e/ou compreensão. É necessário que exista um confronto cognitivo com problemas propostos e a constante reflexão das ideias reveladas (Guimarães, 2009). Sendo assim, o modo pelo qual a atividade experimental é planejada, proposta e conduzida, as reflexões a partir dela originadas e a associação às suas bases conteudinais se sobrepõem à própria metodologia da experimentação (AXT, 1991). Além disso, nenhuma atividade experimental isoladamente logra desenvolver os efeitos esperados em termos de ensino e aprendizagem, tendo em vista a promoção de autonomia intelectual dos sujeitos nela envolvidos (Hodson, 1994).

Nesse sentido, Guridi e Islas (2008) citam alguns critérios que devem ser priorizados no momento da elaboração de uma atividade prática capaz de gerar significados e compreensões. São eles: despertar a motivação dos alunos; identificar e considerar as ideias prévias sobre o fenômeno a estudar e que permitam aos alunos emitir suas próprias hipóteses; desenvolver diferentes formas de experimentação; estimular a discussão entre os grupos de trabalho; propor experiências que enfatizem aspectos qualitativos e não somente quantitativos; introduzir, na medida do possível, a história da Ciência para possibilitar ao aluno conhecer os problemas que permeiam dada comunidade científica em um determinado período e a forma como foram abordados. 
Em conformidade com os autores, acrescentam-se alguns objetivos de uma experimentação de cunho problematizado: motivar o aluno, estimulando seu interesse epistemológico; desenvolver habilidades em laboratório; oportunizar uma aprendizagem significativa de conceitos e princípios científicos; apresentar metodologias científicas e desenvolver raciocínios lógico-dedutivos a partir de sua utilização; promover certas atitudes científicas, tais como objetividade, interpretação e criatividade; coletar, sistematizar, interpretar, compreender e comunicar dados/informações, e transformá-los em resultados. Isso posto, convém destacar que

A situação de formular hipóteses, preparar experiências, realizá-las, recolher dados, analisar resultados, quer dizer, encarar trabalhos de laboratório como "projetos de investigação" favorece fortemente a motivação dos estudantes, fazendo-os adquirir atitudes, tais como curiosidade, desejo de experimentar, acostumar-se a duvidar de certas afirmações, a confrontar resultados, a obterem profundas mudanças conceituais, metodológicas e atitudinais (Lewin \& Lomáscolo, 1998, p. 148).

O registro de dados, muitas vezes pedagogicamente subvalorizado em atividades dessa natureza, pode configurar-se como uma etapa capital à atividade prática, pois eles são elementos basilares e elementares para uma interpretação sofisticada. Originam uma conexão com a dimensão teórica, a semântica do experimento e, com isso, a interpretação do fenômeno. Não que se busquem por "padrões naturais", "revelados" pelo experimento, de resto inexistentes, mas sim pela aplicação de diretrizes de coerência para diferentes leituras por elas validadas. Sendo assim, a AEP deve abranger, desde seu início, um rigor metodológico, indispensável à apropriação epistemológica dos objetivos e objetos pretendidos.

\section{Estrutura Teórico-metodológica Organizadora e Desencadeadora da AEP}

A Atividade Experimental Problematizada (AEP), uma estratégia didático-pedagógica ao ensino experimental das Ciências, está configurada em dois principais eixos, um de natureza teórica e outro metodológica, associativos e potencialmente indissociáveis. Mostrase no Quadro 1, em síntese, seus fundamentos denotativos, tratados como eixos teórico (e seus articuladores) e metodológico (e seus momentos). 
Research, Society and Development, v. 9, n. 7, e187974012, 2020

(CC BY 4.0) | ISSN 2525-3409 | DOI: http://dx.doi.org/10.33448/rsd-v9i7.4012

Quadro 1. Elementos denotativos da AEP: teóricos e metodológicos.

\begin{tabular}{|l|l|}
\hline \multicolumn{2}{|c|}{ Eixos } \\
\hline \multicolumn{1}{|c|}{ TEÓRICO } & \multicolumn{1}{c|}{ METODOLÓGICO } \\
\hline $\begin{array}{l}\text { (a) Proposição de problema } \\
\text { (b) Objetivo experimental } \\
\text { (c) Diretrizes metodológicas }\end{array}$ & $\begin{array}{l}\text { (i) Discussão prévia } \\
\text { (ii) Organização/desenvolvimento } \\
\text { (iii) Retorno ao grupo de trabalho } \\
\text { (iv) Socialização } \\
\text { (v) Sistematização }\end{array}$ \\
\hline
\end{tabular}

Fonte: Silva e Moura (2018).

Sugere-se o planejamento e a condução da AEP sob a sistematização dos eixos referidos, sobre os quais se passará a tratar em maior detalhamento.

\subsection{Eixo teórico da AEP}

Considera-se como eixo teórico da AEP uma configuração que se estrutura a partir da demarcação, elucidação e proposição de um problema de natureza teórica, isto é, uma AEP conforma-se como uma estratégia de busca por solução a dada situação-problema. A partir de então, são elaborados um objetivo experimental, tratando-se do que se espera desenvolver empiricamente em termos de produto e ação experimentais, e diretrizes metodológicas, orientações às ações que virtualmente resultarão no referido produto/ação experimental de interesse. Sendo assim, a AEP propõe uma articulação entre objetivo experimental e diretrizes metodológicas, a partir da proposição e da análise crítica de um problema, para o qual se buscará uma possibilidade de solução, nesse caso particular, pelo uso metodológico da experimentação. Na Figura 1 propõe-se a articulação teórica da AEP. 
Figura 1: Articulação teórica da AEP.

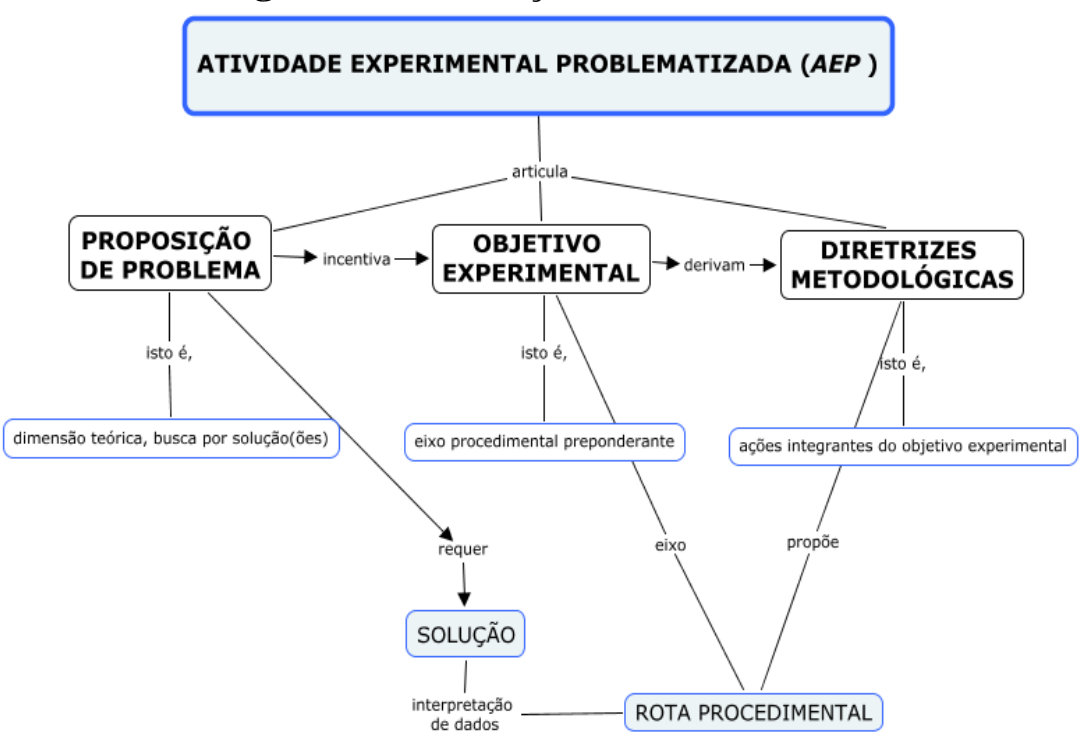

Fonte: Silva; Moura e Del Pino, 2018.

A elaboração, apresentação e elucidação desses eixos configuram-se em atribuições do professor, propositor e organizador da atividade experimental, laboratorial ou por ele deliberado em outro espaço. Em aspectos pormenorizados, se passará na sequência a uma discussão específica de caracterização do problema, objetivo e diretrizes, eixos indispensáveis ao planejamento e à sistematização da asserção.

\section{(a) Problema proposto}

$\mathrm{Na}$ busca por um "[...] planejamento educacional conceitualmente sofisticado e socialmente produtivo"(Eichler \& Del Pino, 1996, p.12), sugere-se a elaboração, identificação e adaptação de um problema (uma situação-problema), capaz de desencadear uma intervenção pedagógica potencialmente significativa, resultando em aprendizagens psicológicas. Na concepção aqui adotada, o problema que origina a AEP requer a elaboração de uma solução, ou sua derivação em novos problemas, distinguindo-se da singularidade de uma questão ou pergunta, as quais se satisfazem por uma resposta.

Problemas privilegiam processos, remetem ao uso de estratégias heurísticas, métodos, técnicas próprias da investigação sistêmica, na busca por uma solução frente a muitas outras que poderiam ser aventadas. Questões/perguntas, por sua vez, atentam-se ao resultado, aceito ou não aceito, isto é, apontam a um fim. Genuinamente, um problema atrela-se a uma situação exigente de maior grau de complexidade, não se podendo atribuir acerto ou erro apenas a partir do que dele resulta, tendo em vista amplas possibilidades metodológicas embutidas em sua condução, das quais os resultados dependerão. Se compreendermos a busca de solução de 
um problema como a articulação de diversos subproblemas, então essa perspectiva se torna quase imediata.

$\mathrm{Na}$ demarcação própria da AEP, esse problema deverá englobar uma natureza teórica, preferencialmente contextualizada, encadeada a unidades conteudinais de interesse. Para sua solução, incentiva a busca por uma rota de ações experimentais adaptativas a diferentes realidades, que levarão a dados que, depois de transformados - coletados, sistematizados, analisados, compreendidos e comunicados - poderão levar a uma perspectiva de solução, qualitativa e/ou quantitativa.

Ao se problematizar informações e observações, desenvolvem-se condições para que elas possam ser efetivamente significativas e socialmente compartilhadas. Com base em Echeverría \& Pozo (1998, p. 15), um problema pode ser definido como “[...] uma situação que um indivíduo ou um grupo quer ou precisa resolver e para qual não se dispõe de um caminho rápido e direto que o leve à solução". Nesse cenário teórico, a proposição de um problema considerado adequado, com foco em um objeto de ensino específico, é capaz de levar os sujeitos a direcionarem informações científicas na busca por uma solução que, ao emergir daquilo que eles previamente conhecem, aproxima essas bases científicas às suas convicções prévias, permitindo a eles estender as Ciências para além da sala de aula, configurando uma coerência lógica cognitiva capaz de tornar seus fundamentos de aplicação significativos. Sacristán (2007, p. 26) argumenta a esse respeito, ao indagar:

[...] que tipo humano estamos formando quando um estudante sabe as regras pelas quais se combinam os elementos químicos, mas não pode explicar as causas e consequências da contaminação do mundo ou o terror da guerra biológica? Por que não se entende que o ensino médio não deve avaliar os estudantes por um conhecimento que, muitas vezes, perdeu o poder de ser uma iniciação à ciência (o que proclama ser) nas matérias do currículo? Para entender o mundo interconectado, é preciso proporcionar conhecimentos interligados.

Não se propõe aqui a aceitação única de soluções esperadas, tampouco a recusa daquelas não cogitadas, mas a permissividade dos sujeitos em defender seus pontos de vista frente ao que considera adequado para solucionar o problema proposto. De modo particular, Freire (1997, p. 82-83) advoga a esse respeito ao sinalizar que "[...] em seu processo, a problematização é a reflexão que alguém exerce sobre um conteúdo, fruto de um ato, ou sobre o próprio ato, para agir melhor, com os demais na realidade”. Sob a fundamentação desse problema, segue-se à elaboração de um objetivo experimental, segundo articulador teórico da AEP. 


\section{(b) Objetivo experimental}

Refere-se a propostas de atividades práticas que operacionalizam a experimentação. Qual técnica é imprescindível à geração de dados, que serão transformados subjacentemente em resultados e, com isso, oferecerão potenciais subsídios práticos à solução do problema proposto? Ao término dos procedimentos empíricos, o que se pretende obter/produzir? Que produto/objeto poderá ser gerado? Portanto, este fundamento pretende conduzir os sujeitos à geração de resultados, mas não necessariamente a uma solução ao problema proposto, visto que tais resultados deverão ser analisados e compreendidos significativamente para tanto.

Desse modo, o objetivo experimentalmente proposto deve servir a um propósito amplo, à busca pela obtenção de um produto teórico a partir de ações processuais, não levando a soluções previamente esperadas e tampouco carente de possibilidades profusas de interpretações, pois um único fenômeno pode ser interpretado à vários modos (Mortimer, 1995). O objetivo experimental, portanto, configura-se como o eixo experimental que norteará a principal ação a ser desenvolvida, isto é, como uma técnica à qual se necessitará de ações capazes de concretizá-la; de proposituras detalhadas. Deriva-se, logo, em diretrizes metodológicas.

\section{(c) Diretrizes metodológicas}

Não sob uma tendência prescritiva, mas reforçando a ideia de orientação procedimental, constituem-se de um protocolo de ações práticas derivadas do objetivo experimental. Atuam como proposituras orientadoras aos procedimentos a serem realizados. Não devem ser admitidas como um fator limitador da experimentação; se defende aqui que a aprendizagem é reduzida ao se tratar da experimentação sob os vieses observacionais ou procedimentais determinísticos. Contudo, tais indicações surgem como uma etapa necessária, a qual oferece o estabelecimento das primeiras ações e norteia os fazeres gerais. Não se reduzem a imposições, podendo ser alteradas/adaptadas a qualquer tempo por professor e/ou alunos. Além disso, visam à inteligibilidade do objetivo proposto e incentivam uma discussão entre os integrantes do grupo de trabalho anterior e concomitante às suas ações, fatores considerados cruciais à organização das ideias individuais e estabelecimento de uma ação conjunta. Sob esta argumentação, sugere-se que problemas propostos distingam-se de suas diretrizes, em natureza e/ou objeto, uma vez que o propósito delas é oferecer respostas ao objetivo experimental, mas não propriamente ao problema proposto, o qual o desencadeia.

Derivando-se, portanto, do objetivo experimental e norteando a busca por seu produto, as diretrizes representam instruções capazes de orientar as ações a serem desenvolvidas 
experimentalmente. São, contudo, flexíveis e adaptáveis. Isto se justifica, em um primeiro momento, ao se reconhecer a importância em se estabelecer as primeiras ações $-e$ organizar as subjacentes - ao favorecer a compreensão dos aspectos técnicos e procedimentais imbuídos na experimentação, elucidando um caminho metodológico adequado ao que se propõe. É imperativo que atividades que abandonam a rígida orientação de procederes possam ampliar o espaço para debates contextualizados entre alunos e professor, proporcionando condições capazes de enriquecer aos processos de ensino e de aprendizagem, visto que a organização de informações com potencialidade de produção de conhecimento ocorre fundamentalmente nos entremeios do fazer experimental (Gil Pérez \& Castro, 1996; Giordan, 1999). E, além disso, ao não se prever indicações de ações iniciais, corre-se o risco de ter de fazê-lo em meio ao processo, tendo em vista questionamentos espontâneos dos alunos ao depararem-se com situações que não dominam, teórica ou operacionalmente.

\subsection{Eixo metodológico da AEP}

Propõe-se o delineamento da AEP por meio de uma sequência metodológica constituída por cinco etapas, caracterizadas como momentos. Institui-se por uma discussão introdutória envolvendo professor e alunos; consolida-se pela materialização de um produto, desenvolvido por esses alunos. Tais momentos, contudo, são dinâmicos e poderão adequar-se aos propósitos específicos e a caracterizações propositais dos sujeitos envolvidos, cabendo sua análise crítica desde o planejamento da atividade, incentivando uma contínua propositura de ações derivadas.

Consideram-se essas ações uma estratégia pedagógica condizente aos seus propósitos de demarcação de uma estrutura teórico-metodológica, tendo em vista uma aprendizagem capaz de gerar significados, não em um formato de rigidez, mas incentivador de um ensino permissivo de reconfiguração de saberes e reconstrução de significados por seus sujeitos. Essas ações, pautadas por temáticas contextualizáveis, são estruturadas a partir da derivação de uma interpretação aberta dos Três Momentos Pedagógicos propostos por Delizoicov e Angotti (1992), a saber: problematização, organização e sistematização do conhecimento, e da Pedagogia Histórico-Crítica proposta por Saviani (2011), metodizada por Gasparin (2005).

Têm-se, com isso, cinco momentos: discussão prévia, organização/desenvolvimento da atividade experimental, retorno ao grupo de trabalho, socialização e sistematização, 
presumidos como imprescindíveis a uma atividade de ensino experimental que ofereça subsídios metodológicos aos aspectos teóricos da AEP, conforme mostra a Figura 2.

Figura 2: Articulação metodológica da AEP.

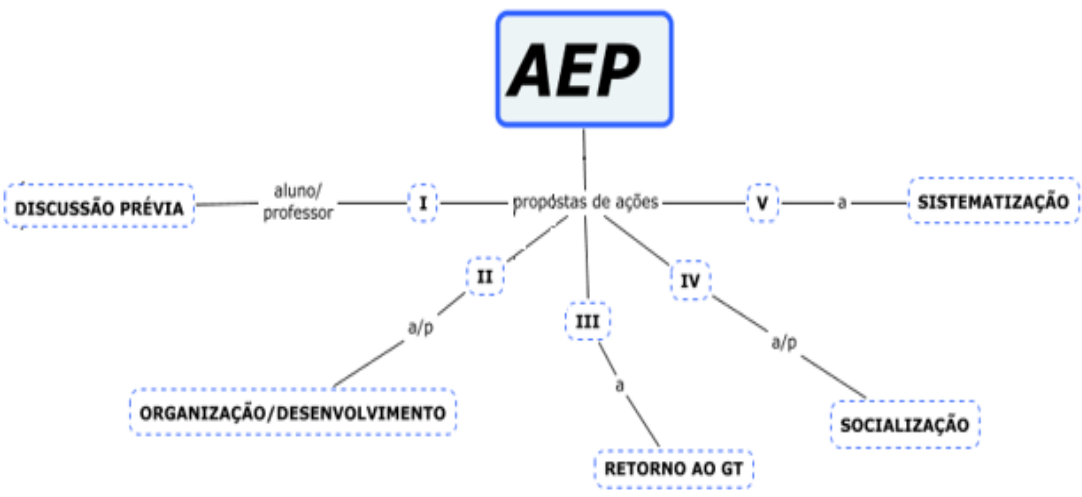

Fonte: Silva; Moura e Del Pino, 2018.

Outras ações, não obstante, de natureza complementar ou ampliativa, poderão ser incorporadas, tomando-se como pressuposto suas contribuições à inteligibilidade no que se refere aos objetos/objetivos de aprendizagem e adequação sistêmica do método à práxis do professor, potencialidade cognitiva dos alunos e a outros fatores imensuráveis e/ou subjetivos. Sendo assim, passa-se a tais cinco momentos, em suas caracterizações e especificidades.

\section{(i) Discussão prévia}

Como ação desencadeadora do processo da AEP propõe-se uma discussão introdutória, em sala de aula ou laboratório, como proposta de identificação dos conhecimentos prévios dos alunos sobre as temáticas principais a serem abordadas. Pode ocorrer por meio de uma discussão teórica, com exposição dialogada de tópicos pontuais às técnicas e seus fundamentos propostos experimentalmente, operacionalizada pela utilização de materiais impressos, como textos, situações contextuais e concretas, questões, questionários abertos ou outro instrumento que se mostrar adequado. $\mathrm{O}$ objetivo central desse momento consiste em apresentar, identificar e desenvolver saberes, com a coparticipação dos alunos.

Em síntese, visa-se investigar o conhecimento inicial dos alunos sobre conteúdos científicos previamente consolidados e suas relações a partir dessas caracterizações e, subjacentemente, introduzir e desenvolver fundamentos científicos teóricos capazes de orientar as próximas etapas do processo. Os conhecimentos disciplinares que subjazem à experimentação devem eclodir nessa etapa, a qual envolve, em sua elaboração, desenvolvimento e avaliação, alunos e professor. 
(CC BY 4.0) | ISSN 2525-3409 | DOI: http://dx.doi.org/10.33448/rsd-v9i7.4012

\section{(ii) Organização/desenvolvimento da atividade experimental}

Essa etapa, de um modo geral, visa à organização procedimental da experimentação. Inicia pela proposição do problema teórico (elaborado, identificado ou selecionado) e de suas derivações em objetivo experimental e diretrizes metodológicas. Avança à implementação coletiva de uma organização ao trabalho experimental, envolvendo a disposição dos alunos em pequenos grupos, com subsequente recomendação para discussões iniciais em cada um desses grupos, seguidas pelo levantamento de hipóteses que contribuam à solução do problema proposto, emergentes dos conhecimentos prévios dos alunos.

Passa-se então propriamente ao desenvolvimento da atividade experimental, onde os alunos realizam a experimentação a partir de sua interpretação própria da AEP, no propósito de “[...] teorizar a prática e praticar a teoria" (PIMENTA, 2011, p. 259). Nesse espaço, registram informações e observações diretas em diário de bordo, por meio de descrições, imagens, tabelas, gráficos, ou qualquer outro recurso pertinente. Conforme Zabala (1998, p. 99), infere-se que “[...] terão que ver, tocar, experimentar, observar, manipular, exemplificar, comparar, etc., e a partir dessas ações será possível ativar os processos mentais que lhes permitem estabelecer as relações necessárias para a atribuição de significado". Essa fase envolve, em sua elaboração, desenvolvimento e avaliação, alunos e professor.

\section{(iii) Retorno ao grupo de trabalho}

No terceiro momento proposto pretende-se favorecer a reflexão e discussão intra grupos de trabalho, seguidas pelo arranjo e sistematização das informações registradas. Após a realização da atividade experimental é solicitado aos alunos que retornem ao seu grupo para ordenação dos registros que julgarem pertinentes. Nessa fase, passam ao desenvolvimento cognitivo balizador de uma compreensão dos dados experimentais obtidos, a serem transformados em resultados emergentes de uma interpretação conjunta dialógica com perspectivas de solução ao problema proposto, o qual instaurou a atividade.

Defende-se, no contexto da AEP, que um experimento deve estender-se para além da simplicidade das manipulações e dos registros, pois compreensões psicológicas são geradas pela aplicabilidade que os sujeitos desenvolvem aos dados empíricos obtidos. Ao retornar aos seus pares, passivam-se ao desenvolvimento de um tratamento de dados/informações capaz de levá-los a uma solução ao problema originário das atividades, geradora de convencimento coletivo, pela logicidade argumentativa que poderá apresentar. Essa etapa do processo envolve, em sua elaboração e desenvolvimento, fundamentalmente os alunos. O professor, em 
sua avaliação, deve se aproximar de cada grupo, mantendo um posicionamento de neutralidade, analisando in loco saberes/fazeres decorrentes.

\section{(iv) Socialização}

Tendo em vista a prevalência de uma relação ensino-aprendizagem processual, que subvaloriza os produtos finais obtidos e incentiva a busca constante por soluções e por novos questionamentos durante todo processo, o momento da socialização ganha relevância, pois "demonstrará" os caminhos metodológicos seguidos a partir das justificativas das quais cada grupo utilizará ao defender seus resultados e uma possível solução ao problema desencadeador da AEP. A partir do confronto entre argumentações distintas pode-se seguir a uma possível generalização, tendo em vista os encaminhamentos dados pelo professor.

O momento da socialização objetiva incentivar um diálogo entre os diferentes grupos de trabalho, tendo em vista distinções teórico-metodológicas que poderão levar a resultados e a conclusões consideravelmente dissemelhantes. Consiste no oferecimento de um espaço coletivo à troca de ideias referentes aos procedimentos realizados durante a técnica; concepções de acertos e erros experimentais e perspectivas de autoconvencimento seguida pela elaboração de uma explicação teórica qualificada a oferecer solução coletiva ao problema proposto. Conforme Freire (1997, p. 42), “[...] todo entendimento [...] implica, necessariamente, comunicabilidade". Nesse cenário, se oferece um espaço aberto para amplas discussões, as quais poderão retornar aos aspectos teóricos envolvidos, conforme as diretrizes efetivamente utilizadas no desenrolar do processo. Essa fase envolve, em sua elaboração, desenvolvimento e avaliação, alunos e professor.

\section{(v) Sistematização}

Reputa-se aqui à geração de um produto como ação imprescindível à aprendizagem. Esta estratégia permite a sistematização e o registro das percepções geradas em sua possível derivação a uma solução aceitável ao problema proposto. Configura-se, contudo, como uma atividade que deve apresentar certa individualidade. Pode-se utilizar de material impresso como subsídio teórico, seguido por uma produção textual pelo aluno a partir dos conhecimentos que produziu em torno das informações manipuladas, coletadas e/ou produzidas. Pode se fazer uso de questões orientadoras e/ou de seções protocolares, que promovam sistematizações e a aplicação de conclusões a outras realidades. Essas perspectivas de articulação a outros contextos/objetos de aplicação devem ser supervalorizadas, sendo que uma aprendizagem é caracterizada não propriamente pelo conhecimento dela resultante, mas 
pela capacidade do aprendiz em levar esse conhecimento à sua prática, tendo em vista sua competência de ação (Zabala, 1998).

Normalmente, após o desenvolvimento de uma técnica experimental, é solicitada a produção de um relatório, entregue por grupo de trabalho. Essa estratégia pode ser mantida, desde que se ofereçam diretrizes à sua feitura, não em uma padronização rígida - uma vez que sua função não é profissionalizante, mas pedagógica - mas no intuito de oferecer aos alunos subsídios quanto a um modo coerente pelo qual poderão apresentar seus resultados e estruturar os produtos de suas observações, característica constitutiva da comunicação científica, em sua exigência de reprodutibilidade (SILVA; MOURA, 2018).

Esse momento correlaciona-se diretamente ao primeiro, o qual investigou $o$ conhecimento prévio dos alunos com relação ao tema circunscrito e desenvolveu um aprofundamento científico em vista ao estabelecimento de uma nova estrutura cognitiva, reconfigurando informações nela previamente existentes e propondo novas. Genuinamente, é capaz de oferecer ao professor importantes unidades avaliativas que verifiquem indícios da eficiência e eficácia dos processos de ensino e de aprendizagem, em sua dimensão significativa. Com isso, pretende-se consubstanciar uma tríade teórico-metodológica constituída por reflexão - pesquisa - produção. Envolve, em sua elaboração e desenvolvimento, fundamentalmente os alunos. O professor desempenha a função de avaliador do processo.

\section{Considerações Finais}

Conforme defendido neste artigo, as atividades experimentais consistem de uma metodologia altamente contributiva ao ensino e à aprendizagem das Ciências, pois ampliam as potencialidades de professores e alunos em estabelecerem uma interação proposicional, subsidiada por argumentos e ideias do universo das Ciências. Com isso, permitem tornar a ação do aluno mais ativa e superaram uma visão pouco problematizada da Ciência tratada em sala de aula.

A experimentação, sob essa conjuntura, consolida-se como um experiente capaz de considerável contribuição na explicitação, problematização e discussão de conceitos/princípios/teorias, no âmbito teórico, bem como de habilidades e competências, em um domínio técnico.

Contudo, considera-se que, tal como ocorre a toda estratégia metodológica aventada, há imprescindibilidade de uma conformação teórico-metodológica, isto é, de uma sistematização, 
capaz de oferecer a base e estrutura necessárias a se utilizar da experimentação com propósitos pedagógicos.

À guisa disso, se tratou neste artigo acerca da Atividade Experimental Problematizada (AEP), potencialmente condizente ao que se propõe, um Ensino de Ciências experimental capaz de gerar significados e contribuir à construção de um conhecimento científico com efetiva compreensão de seus aspectos circunscritos.

\section{Referências}

Axt, R. (1991). O papel da experimentação no Ensino de Ciências. In: MOREIRA, M. A.; Axt, R. Tópicos em ensino de Ciências. Porto Alegre: Sagra.

Cachapuz, A.; Gil-Perez, D.; Carvalho, A.M.P.; Praia, J.; Vilches, A. (2005). A necessária renovação do ensino das ciências. São Paulo: Cortez.

Carvalho, A. M. P. Vannucchi, A. I. \& Barros, M. A. (2007). Ciências no Ensino Fundamental: o conhecimento físico. São Paulo: Scipione.

Delizoicov, D. \& Angotti, J. A. (1992). Metodologia do Ensino de Ciências. São Paulo: Cortez.

Echeverría, M. D. P. P. \& Pozo, J. I. (org.) (1998). Aprender a resolver problemas e resolver problemas para aprender. In: Pozo, J. I. (Org.). A solução de problemas: aprender a resolver, resolver para aprender. Porto Alegre: Artmed.

Eichler, M. L. \& Del Pino, J. C. (1996). Ambientes virtuais de aprendizagem: desenvolvimento e avaliação de um projeto de educação ambiental. Porto Alegre: Editora da UFRGS.

Francisco Jr., W. E., Ferreira, L. H. \& Hartwig, D. R. (2008). Experimentação problematizadora: fundamentos teóricos e práticos para a aplicação em salas de aula de ciências. Química Nova na Escola. 30(1): 34-41. 
Freire, P. (1997). Pedagogia da autonomia: saberes necessários à prática educativa. São Paulo: Paz e Terra.

Galiazzi, M. C. \& Gonçalves, F. P. (2004). A natureza pedagógica da experimentação: uma pesquisa na licenciatura em química. Química Nova. 27(2): 326-331.

Gasparin, J. L. (2005). Uma didática para a Pedagogia Histórico-Crítica. 3.ed. São Paulo: Autores Associados.

Gil Perez, D. (1993). Tres paradigmas básicos en la enseñanza de las Ciencias. Ensenãnza de las Ciencias. 1(1): 26-33.

Gil Perez, D. \& Castro, P. V. (1996). La orientacion de las practicas de laboratorio como investigación: un ejemplo ilustrativo. Enseñanza de las Ciencias. Barcelona, 14(2): 155- 163.

Giordan, M. (1999). O papel da experimentação no Ensino de Ciências. Química Nova na Escola. 10(1): 43-49.

Guimarães, C. C. (2009). Experimentação no Ensino de Química: caminhos e descaminhos rumo à Aprendizagem Significativa. Química Nova na Escola. 31(3): 198-202.

Guridi, V. M. \& Islas, S. M. (2008). Guías de laboratorio tradicionales y abiertas en física elemental propuesta para diseñar guías abiertas y estudio comparativo entre el uso de este tipo de guias y guias tradicionales. Investigação em Ensino de Ciências. 13(3): 203-220.

Hodson, D. (1994). Hacia un enfoque más crítico del trabajo de laboratorio. Enseñanza de las Ciencias. 12(3).

Latour, B. \& Woolgar, S. (1997). A vida de laboratório. Rio de Janeiro: Relume Dumará.

Lewin, A. M. F. \& Lomáscolo, T. M. M. (1998). La metodologia cientifica em la construcción de conocimientos. Revista Brasileira de Ensino de Física. São Paulo, 20(2): 147-154. 
Moreira, J. R., Silva, A. L. S., Moura, P. R. G. \& Del Pino, J. C. (2019). Potencialidade de um plano de ensino pautado na Atividade Experimental Problematizada (AEP) à Alfabetização Científica em Química. Experiências em Ensino de Ciências. 14(2).

Mortimer, E. F. (1995). Concepções atomistas dos estudantes. Química Nova na Escola. 1(1): 23-26, mai.

Mortimer, E. F., Machado, A. H. \& Romanelli, L. I. A. (2000). Proposta curricular de Química do Estado de Minas Gerais: fundamentos e pressupostos. Química Nova. São Paulo, 23(2): 273-283, mar./abr.

Perrenoud, P. (2000). Dez novas competências para ensinar. Porto Alegre, ARTMED.

Pimenta, S. G. (Org.). (2011). Didática e formação de professores: percursos e perspectivas no Brasil e em Portugal. $6^{\circ}$ ed. São Paulo: Cortez.

Pozo, J. I. (org). (1998). A solução de problemas: aprender a resolver, resolver para aprender. Porto Alegre: Artmed.

Sacristán, J. G. (2007). A educação que ainda é possível: ensaios sobre uma cultura para a educação. Porto Alegre: Artmed.

Santos, W. L. P. (2008). Educação científica humanística em uma perspectiva freireana: Resgatando a Função do Ensino de CTS. Alexandria Revista de Educação em Ciência e Tecnologia. 1(1): 109-131.

Saviani, D. (2011). Pedagogia Histórico-Crítica: primeiras aproximações. 10.ed., Campinas, SP: Autores associados.

Silva, A. L. S., Moura, P. R. G. \& Del Pino, J. C. (2015). Atividade Experimental Problematizada: uma proposta de diversificação das atividades para o Ensino de Ciências. Experiências em Ensino de Ciências. 10(3). 
Silva, A. L. S., Moura, P. R. G. \& Del Pino, J. C. (2017). Atividade Experimental Problematizada (AEP) como uma estratégia pedagógica para o Ensino de Ciências: aportes teóricos, metodológicos e exemplificação. Experiências em Ensino de Ciências, 12(5).

Silva, A. L. S., Ferreira, M., Pereira, S. M. \& Filho, O. L. S. (2019). Atividade Experimental Problematizada (AEP): revisão bibliográfica em descritores na área de Ensino de Ciências. Revista Pesquisa e Debate em Educação, 9(1).

Silva, A. L. S., Moura, P. R. G. \& Del Pino, J. C. (2018). Subsídios pedagógicos e epistemológicos da Atividade Experimental Problematizada. REVELLI. 10(4), dezembro.

Silva, A. L. S. \& Nogara, P. A. (2018). Atividade Experimental Problematizada (AEP) - 60 experimentações com foco no ensino de Química: da educação básica à universidade. Appris. Curitiba/PR.

Silva, A. L. S. \& Moura, P. R. G. (2018). Ensino Experimental de Ciências - uma proposta: Atividade Experimental Problematizada (AEP). Livraria da Física. São Paulo/SP.

Zabala, A. (1998). A prática educativa: como ensinar. Porto Alegre: Artmed.

\section{Porcentagem de contribuição de cada autor no manuscrito}

André Luís Silva da Silva - 50\%

Paulo Rogério Garcez de Moura - 25\%

Pablo Andrei Nogara - 25\% 